\title{
Correction: Suicide mortality among people accessing highly active antiretroviral therapy for HIV/AIDS in British Columbia: a retrospective analysis
}

An error occurred in an article published Apr. 8, 2015. ${ }^{1}$ The rate of death from suicide in 2010 was incorrectly reported as 2.81 deaths per 100000 person-years. The 2010 rate should have been reported as 28 deaths per 100000 person-years. The error appeared in the results section of the abstract and the article. It has been corrected at cmajopen.ca.

\section{Reference}

1. Gurm J, Samii H, Nophal A, et al. Suicide mortality among people accessing highly active antiretroviral therapy for HIV/AIDS in British Columbia: a retrospective analysis. CMAF Open 2015;3:E140-8.

CMAJ Open 2018. DOI:10.9778/cmajo.20180197 